\title{
U.S. INSTITUTE FOR BIOMEDICAL RESEARCH
}

\begin{abstract}
$\mathrm{A}^{\mathrm{N}}$ Institute for Biomedical Research is to be established by the American Medical Association Education and Research Foundation and will be officially opened on July 1, 1965. Laboratory and animal research facilities for the Institute will be located in a new addition to the American Medical Association headquarters building in Chicago, now under construction.

A committee has been set up under the chairmanship of Prof. Maurice B. Visscher, chairman of the Department of Physiology of the University of Minnesota Medical School, to advise the Board of the American Association Educa. tion and Research Foundation on the qualifications of prospective members of the Institute's scientific staff and to recommend specific applications of policies.

Other members of the committee are Prof. William H. Feldman, chief of laboratory research in pulmonary diseases for the Veterans Administration, Washington, D.C.; Prof. Chauncey D. Leake, Department of Pharmacology, University of California School of Medicine, San Francisco; Prof. Donald D. Van Slyke, member emeritus of the Rockefellor Institute, of Brookhaven National Laboratory, Upton, New York; Prof. Henry Eyring, dean of the University of Utah Graduate School, Salt Lake City, and president-elect of the American Association for the Advancement of Science.

The purposes and policies of the Institute are delineated as follows:
\end{abstract}

(1) "To provide appropriate personnel, facilities, and conditions, conducive to obtaining significant, basic bio- medical information which oventually may be applied to promoting the good health of people.

(2) "The personnel, nominated by the Committee of Scientific Advisors, will include biomedical scientists of the best possible stature or promise with such secretarial and technical assistance as may be appropriate to their respective activities, and with such Post-doctoral Fellows as may be attracted by the individual investigators in relation to their facilities and scientific interests.

(3) "Initial laboratory facilities will include 30,000 square feet of space to be set up and equipped on the recommendations of the scientific personnel and the Committee of Scientific Advisors, together with appropriate quarters and caro for experimental animals. Extensivo library facilities will be available through the headquarters organization of the American Medical Association.

(4) "Every possible effort will be made to establish such conditions in the Institute as will be stimulating for basic biomedical investigation in accordance with the highest scientific standards and ideals. The organizational policies of the American Medical Association provide liberal financial security and perquisites. Responsible freedom in research and publication is assured. The Institute is expected to maintain tho best possible intellectual environment for supporting investigation into fundamental biomedical scientific problems."

\section{C.S.I.R.O. PHYSICS IN AUSTRALIA}

\begin{abstract}
$\mathrm{T}$ HE Divisions of Applied Physics and of Physics of the Commonwealth Scientific and Industrial Research Organization, Australia, are situated at Sydney and form the National Standards Laboratory. The Applied Physics Division is responsible for the establishment and maintenance of mechanical standards of measurement of length, mass and time, and associated measurements, and of electrical standards of measurement. The Division of Physics has similar responsibility for standards in heat, light, viscometry and hygrometry. The annual reports of the Divisions for 1962-63, together with those of the Divisions of Tribophysics and of Meteorological Physics situated at Melbourne have recently been issued*.

The work done in the Division of Applied Physies on the reproducibility of the orange-red radiation of krypton-86 as the primary standard of length, and on other secondary standards, was reported at the 1962 meeting in Paris of the advisory committee on the definition of the metre. A now version of the Fabry-Perot scanning interferometer in use in the division is being designed. A precise quartzscale and photoelectric microscope for rapid measurement of changes of plate separation to within one order of interference and up to $500 \mathrm{~mm}$ are to be incorporated. Alterations are being made to the $1-\mathrm{m}$ line standard comparator. The $0 \cdot 1$-in.-wide thin soft-metal strip to be used in the determination of the gyromagnetic ratio of the proton has been measured and an accuracy of $8 \times 10^{-6}$ in.

* Commonwealth Scientific and Industrial Research Organization. Annual Report of the Division of Applied Physies, 1962-63. Pp. vi +45 . Annual Report of the Division of Physics, 1962-63. Pp. $v+28$. Annual Report of the Division of Meteorologieal Physics, 1962-63. Pp. ii +20 . Annual Report of the Division of Tribophysics, 1962-63. Pp. 1 18 . (Commonwealth Scientific and Industrial Research Organization: Sydney and Melbourne, 1963.)
\end{abstract}

achieved in the measurement of the thickness. Steady progress has been made on the construction of the equip. ment for the absolute determination of gravity by the rise-and-fall method. An accurate bolometer bridge has been developed for the measurement of power at radio and microwave frequencies, and work on magnetic viscosity has been extended by the provision of equipment for the measurement of both loss and permeability as a function of either time or frequency at temperatures up to the Curie temperature. In connexion with the 210 -ft. radio telescope at Parkes, New South Wales, a detailed study has been made of the vibration modes of telescope structures.

In the Division of Physics results have been obtained which indicate that the freezing-points of pure tin $\left(231.912^{\circ} \mathrm{C}\right)$ and pure cadmium $\left(321.032^{\circ} \mathrm{C}\right)$ are worthy of consideration as reference points for platinum resistance thermometry on the International Practical Temperature Scale. There is a continuous demand for consultations on techniques of temperature measurement, and inspections of laboratories on behalf of the National Association of Testing Authorities for the purpose of registration in the field of heat and temperature measurement have continued. Additional qualified laboratories are still needed. The measurement of the thermal conductivity of unirradiated and irradiated $\mathrm{BeO}$ at low temperatures, the specific heat of silver below $4^{\circ} \mathrm{K}$, and the linear expansion of alkali-halide crystals, germanium and silicon and anisotropic metals at temperatures below $20^{\circ} \mathrm{K}$, form part of the solid-state physics research activities of the division. There are facilities for a wide range of precision optical measurements, particularly for interferometry and the 